\title{
Manganese dioxide nanoparticle induces Parkinson like neurobehavioral abnormalities in rats
}

\author{
Sadeghi L ${ }^{1}$, Yousefi Babadi V², Tanwir $\mathrm{F}^{3}$ \\ Department of Animal Biology, Faculty of Natural Science, University of Tabriz, Tabriz, Iran. \\ v.yoosefi@gmail.com
}

\begin{abstract}
AIM: Manganese dioxide magnetic nanoparticle $\left(\mathrm{MnO}_{2}-\mathrm{NP}\right)$ with specific size range from 30 to $60 \mathrm{~nm}$ has widespread application in magnetic resonance imaging, medicine and drug delivery in exposed humans and animals. Manganese nanoparticles could affect hippocampus tissue and impose abnormal cognitive functions such as manganese ion. Therefore, to investigate whether $\mathrm{MnO}_{2}-\mathrm{NP}$ is damaging hippocampus tissue and inducing molecular and neurobehavioral abnormalities, we administrated different doses of synthesized nanoparticle to rats and measured behavioral, biochemical and histological parameters by standard methods.

RESULTS: Results showed that the treatment of rats with $\mathrm{MnO}_{2}-\mathrm{NP}$ during 15 days induced oxidative stress and reduced catecholamine content in hippocampus tissue. $\mathrm{MnO}_{2}-\mathrm{NP}$ affected hippocampus tissue appearance by increasing the number of apoptotic and necrotic cells suggested that approved nanoparticle penetrated blood brain barrier and reached the hippocampal cells. Interestingly, all biochemical and histological effects of $\mathrm{MnO}_{2}$ NP were dose dependent.

CONCLUSIONS: By considering that hippocampus plays an important role in cognitive function, behavioral abnormalities in intoxicated rats were predictable and nanoparticle administrated rats showed depression like behavioral signs dose dependently. Based on our results and previous studies that confirmed neurotoxicity of $\mathrm{MnO}_{2}-\mathrm{NP}$ in $\mu \mathrm{g}$ dose rang, the application of this nanoparticles should be limited and their waste should be neutralized before their release to the environment (Fig. 4, Ref. 31). Text in PDF www.elis.sk

KEY WORDS: cognitive disorders; nano-sized materials; nano toxicity; central nervous system susceptibility.
\end{abstract}

\section{Introduction}

Nanoparticles with a size between 10-100 nm have exclusive physical and chemical properties such as: special shape, high surface area to volume ratio, penetrating through cell membrane and blood brain barrier (1). All of these features make them unique for biological, medical and industrial applications (2). Manganese dioxide nanoparticle $\left(\mathrm{MnO}_{2}-\mathrm{NP}\right)$ is one of the most useful magnetic nano-size materials that have widespread applications in medical science such as: magnetic resonance imaging (MRI), ultrasound, biosensor, optical imaging and drugs delivery (2). Useful features of $\mathrm{MnO}_{2}-\mathrm{NP}$ make it a unique compound for industry as well (magnetic data storage, textiles, coatings, nanowires, plastics, and nanofibers) (3). By considering a wide application of manganese nanoparticles in medicine, biology and industry, exposure of humans to this toxicant is inevitable $(2,4)$. While this toxic material is released to the environment after use, it affects animals and also plants. Systemically administrated $\mathrm{Mn}^{2+}$ ion is mainly accumulated in central nervous system (CNS) and dam-

${ }^{1}$ Department of Animal Biology, Faculty of Natural Science, University of Tabriz, Tabriz, Iran, ${ }^{2}$ Department of Physiology, Payam Noor University of Iran, Iran, and ${ }^{3}$ Matrix Dynamics Group, University of Toronto, Canada

Address for correspondence: L. Sadeghi, Subdivision of Biochemistry, Department of Animal Biology, Faculty of Natural Science, University of Tabriz, Tabriz, Iran, P.O. Box 5166616471, Tabriz, Iran.

Phone: +9841.35442617 ages it as previously approved (5). Previous studies confirmed $\mathrm{Mn}^{2+}$ overdosing causes Parkinson like disorder known as manganism, which is accompanied by tremors, odd movements, mask like face, and body stiffness that was first observed in miners (6). Our prior results also showed that an acute dose of $\mathrm{Mn}^{2+}$ caused catecholamine reduction in brain tissue by unknown mechanism (7). According to literature, one of the affected tissues in $\mathrm{Mn}^{2+}$ toxicity is hippocampus that has an important role in hippocampaldependent learning and memory, depressive-like behaviors and cognitive disorders similar to manganism $(8,9)$. The main goal of this study was to investigate the $\mathrm{MnO}_{2}-\mathrm{NP}$ toxic effects on the rat hippocampus by biochemical analysis, behavioral assessment and histological studies. Our prior results showed that $15 \mathrm{mg} / \mathrm{kg}$ $\mathrm{Mn}^{2+}$ imposed behavioral and molecular abnormalities referring to manganism (unpublished data). By considering a small size and high reactive surface area of $\mathrm{MnO}_{2}-\mathrm{NP}$ rather than chemical $\mathrm{Mn}^{2+}$ ion (1), this study used lower dose of toxicant nanoparticle at the microgram level. Due to dose dependent assessment of hippocampal damages and behavioral abnormalities, two different doses of magnetic nanoparticle were used in this study.

\section{Materials and methods}

\section{Chemicals}

2,7 dichlorofluorescindiacetate (DCFHDA), thiobarbituric acid, and 5,5'-Dithiobis (2-nitrobenzoic acid) were prepared from 
Sigma Chemical Company. All other solvents and chemicals were of the highest grade-commercially available. $\mathrm{MnO}_{2}$ nanoparticles were prepared via the hydrothermal procedure with some modification (10). In order to prepare nanoparticle, $20 \mathrm{ml}$ of $\mathrm{KMnO}_{4}(0.2$ $\mathrm{mM})$ were mixed with $16 \mathrm{ml} \mathrm{MnO}_{4}(0.125 \mathrm{mM})$ for 5 minutes. The final solution was warmed in a steel autoclave with Teflon cover up to $160{ }^{\circ} \mathrm{C}$ and kept in $160^{\circ} \mathrm{C}$ overnight and then was cooled at room temperature (11). The resulting brown product was collected, washed with distilled water and ethanol 3 times, and dried with the hot air current for $12 \mathrm{~h}$. The resulting particles were dispersed by sonication (10 $\mathrm{min}, 750 \mathrm{~W}$ and $20 \mathrm{kHz}$ ) in physiological saline (pH 7). Size distribution and nanoparticle dispersion were confirmed by dynamic light scattering (DLS) experiment and TEM imaging. As shown in Figure 1, size range of $\mathrm{MnO}_{2}-\mathrm{NP}$ was from 30 to 60 $\mathrm{nm}$, TEM imaging also confirmed well dispersion of nanoparticles by sonication.

\section{Experimental design}

In vivo study was conducted on experimental animals, using adult male Wistar rats weighing 250-300 g, obtained from the animal house of martyr portal. Rats with the average age of 4.5-6 months were selected. Keeping the animals and the testing was carried out at temperature of $20-25^{\circ} \mathrm{C}$ and the day duration was 12 hours and dark period was 12 hours. Municipal tap water was used as drinking water and animal feed as nutrition (compressed company prepared feed was used). We had three experimental groups in this study and 8 rats in each group. The first group was injected with physiological saline $(0.9 \% \mathrm{NaCl})$ for 15 days, the second group was injected daily with $50 \mu \mathrm{g} / \mathrm{kg} \mathrm{MnO}_{2}-\mathrm{NP}$ in saline as solvent during 15 days and the third group was treated by intraperitoneally injected $100 \mu \mathrm{g} / \mathrm{kg} \mathrm{MnO}_{2}-\mathrm{NP}$ in saline during 15 days. Treated rats were used for biochemical, behavioral and histological analysis after experimental time course and $24 \mathrm{~h}$ after the last injection.

\section{Behavioral assessment}

Forced swimming test

A transparent plexiglass cylinder $(20 \mathrm{~cm}$ diameter and $50 \mathrm{~cm}$ height) filled with warm water $\left(25^{\circ} \mathrm{C}\right.$ and $30 \mathrm{~cm}$ depth) was used based on the standard protocol (12). According to classic procedure, rats were placed in the cylinder during a two-day protocol. The first day of habituation, the rats were forced to swim for 15 min; $24 \mathrm{~h}$ after, on the test day, three categories of behavioral activity (climbing, swimming and immobility) were recorded during the 5 min test period. Immobilization time was considered as the time between introducing a rat into the pool and the time during which the rats remained floating motionless on the water. After each test, the rats were dried immediately and kept warm before returning to their home cage.

\section{Sucrose preference test (SPT)}

Sucrose preference test is one of the usual tests for depression like behavior evaluation in rodents that assesses toxicity imposed anhedonia by standard protocol (13). The rats were placed in individual cages with sufficient food and water. At first, rats were adapted to having two water bottles in the cage lid for 72 hours and position of the bottles was randomly changed as many times as possible to avoid a place preference. In order to prevent fluid leak, the bottles were fitted with ball-bearing sipper tubes. After adaptation time course, rats had the free choice of either bottle for water drinking. Then one of the bottles was filled with $1 \%$ sucrose solution during 48 hours test. Water and sucrose solution intake was measured daily. The locations of two bottles were switched daily to reduce side bias. Sucrose preference was calculated as follows: [sucrose consumption (g)/(sucrose consumption $(\mathrm{g})+$ water intake $(\mathrm{g}))]^{*} 100$. The average sucrose consumption was reported for two-day test.

\section{Catecholamine concentration measurement}

24 hours after the last injection, rats were anesthetized and hippocampus was separated from sculpture. Fresh hippocampus tissue or tissue that was frozen in liquid nitrogen and stored at -80 ${ }^{\circ} \mathrm{C}$ were homogenized in cold $0.05 \mathrm{~N} \mathrm{HClO}_{4}$ containing dihydroxybenzylamine as an internal standard (14). The supernatant following centrifugation at $12,000 \times \mathrm{g}$ for 15 minutes was processed according to Felice et al, except that $0.1 \mathrm{~N} \mathrm{HClO}_{4}$ was required to

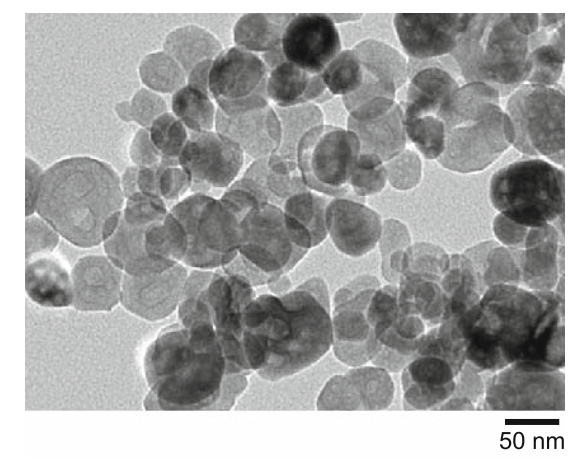

Fig. 1. Characterization of manganese dioxide nanoparticles $\left(\mathrm{MnO}_{2}-\mathrm{NP}\right)$. A: Dynamic light scattering result approved diameters of synthesized nanoparticles are between 30 and $60 \mathrm{~nm}$. B: TEM micrographs of $\mathrm{MnO}_{2}$-NP confirmed a good shape and good dispersion of nanoparticles by sonication. 
elute the amines from the alumina (15). Catecholamine in alkaline environment and in the presence of ascorbic acid and iodine as a strong oxidant agent convert to fluorescent substance (16). Catecholamine concentration measurement was done by fluorescence spectroscopy with a Perkin Elmer luminescence spectrometer LS 55. The excitation wavelength was set at $405 \mathrm{~nm}$ and the emission spectra were recorded in $515 \mathrm{~nm}$. Excitation and emission slit were both set at $5 \mathrm{~nm}$.

\section{Reactive oxygen species (ROS) measurement}

ROS generation was measured according to the methods of Lebel et al. (1992) with some modifications that evaluated the oxidative conversion of DCFH-DA to dichlorofluorescin (DCFH) as a fluorescent compound (17). Hippocampus homogenates were diluted 1:10 in buffer to obtain a concentration of $2.5 \mathrm{mg}$ tissue $/ 500$ $\mu 1$. Then, the homogenates were pipetted into 24 -well plates (450 $\mu \mathrm{l} /$ in each well) and allowed to warm to room temperature for 5 min. At that time, $5 \mathrm{ml}$ of DCFH-DA (10 $\mathrm{mM}$ final concentration) was added to each well and the plates were preincubated for 15 min at room temperature to allow the DCFH-DA to be incorporated into any membrane-bound vesicles and the diacetate group cleaved by esterases. After the preincubation, $50 \mathrm{ml}$ of the appropriate concentration of $\mathrm{Fe}^{2+}$ was added to the wells. After $30 \mathrm{~min}$, DCFH-DA converted into fluorescent DCF during reaction with ROS. DCF fluorescence was determined at $485 \mathrm{~nm}$ excitation and $530 \mathrm{~nm}$ emission using a (Perkin Elmer luminescence spectrometer LS 55) fluorescence spectrophotometer. The slit width was $5 \mathrm{~nm}$ for both excitation and emission. Protein concentration in homogenates was determined using Bradford method (18) and did not differ among the groups.

\section{Lipid peroxidation (LPO) measurement}

We measured lipid peroxidation as a marker of oxidative stress in hippocampus tissue (19). Hippocampus tissue was homogenized with ice cold buffer containing $0.15 \mathrm{M} \mathrm{KCl}$ to obtain $1: 10(\mathrm{w} / \mathrm{v})$ homogenates. Aliquots of homogenate $(1 \mathrm{ml})$ were incubated at $37{ }^{\circ} \mathrm{C}$ for $3 \mathrm{~h}$ in a shaker. Then, $1 \mathrm{ml}$ of $10 \%$ aqueous trichloroacetic acid (TCA) was added and mixed. The mixture was then centrifuged at $800 \mathrm{~g}$ for $10 \mathrm{~min}$. Then, supernatant $(1 \mathrm{ml})$ was mixed with $1 \mathrm{ml}$ of $0.67 \%$ thiobarbituric acid and warmed in a boiling water bath for $10 \mathrm{~min}$. The mixture was cooled and diluted with $1 \mathrm{ml}$ of distilled water. MDA is the final product of lipid peroxidation reaction with tiobarbitouric acid or TBA (this reaction was complete in $100{ }^{\circ} \mathrm{C}$ ) and released TBARS could absorb 532 $\mathrm{nm}$ light (20). The results were expressed as the percent of MDA production compared to the control.

\section{Statistical evaluation}

Data in all the experiments were expressed as the mean \pm standard error of mean (S.E.M). Data were analyzed by SPSS version 11 using one-way ANOVA followed by the post-hoc Duncan multiple range test. Differences were considered significant at $\mathrm{p}<0.05$.

\section{Results}

$\mathrm{MnO}_{2}-\mathrm{NP}$ imposed neurobehavioral abnormalities in treated rats

We intraperitoneally injected rats with 50 and $100 \mu \mathrm{g} / \mathrm{kg}$ $\mathrm{MnO}_{2}-\mathrm{NP}$ (based on previous experiments) and assessed behavioral and biochemical parameters and histological alterations as well. We monitored the mortality rate, food consumption, water intake, and body weight dynamic of the experimental groups during the study. The results showed that water/food and survival of rats were not changed significantly in treated rats during the experiment. Body weight progressive curve was not affected significantly by any dose of $\mathrm{MnO}_{2}-\mathrm{NP}$ treatment (data not shown).

\section{Forced swimming test}

The forced swimming test (FST) was done to assess a depressive-like behavior in rats intraperitoneally treated by $\mathrm{MnO}_{2}(12)$. Immobility time for experimental groups was recorded as follows: control rats that received saline instead of nanoparticle were immobilized after $17.20 \mathrm{sec}, 50 \mu \mathrm{g} / \mathrm{kg} \mathrm{MnO}_{2}-\mathrm{NP}$ treated rats were immobilized after $78.23 \mathrm{sec}$ and rats that received $100 \mu \mathrm{g} / \mathrm{kg}$ were immobilized after $110.45 \mathrm{sec}$. Therefore, $\mathrm{MnO}_{2}-\mathrm{NP}$ treatment significantly increased the immobility time in dose dependent manner (Fig. 2).

\section{Sucrose preference test}

Nanoparticle induced anhedonia was measured by sucrose preference test after 15 days experiment as the standard method SPT (13), so we used this test for anhedonia assessment in $\mathrm{MnO}_{2}-$ NP treated rats and the controls. This study revealed that sucrose consumption was significantly decreased in rats that received $\mathrm{MnO}_{2}$-NP in dose dependent manner (Fig. 2). Sucrose intake in rats administrated with $50 \mu \mathrm{g} / \mathrm{kg}$ was $62.23 \pm 6.23 \%$, in rats received $100 \mu \mathrm{g} / \mathrm{kg}$ was $45.23 \pm 5.16 \%$ and in rats treated by saline was $90.51 \pm 7.94 \%$.

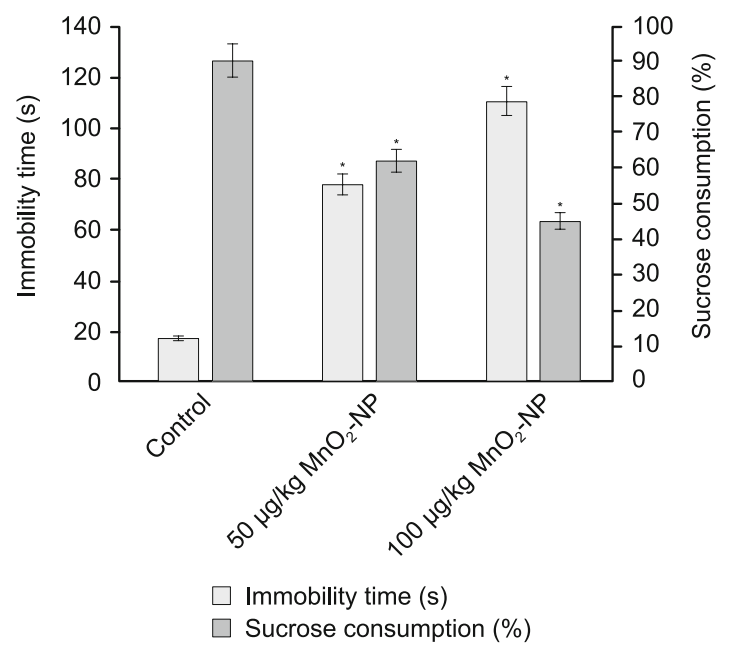

Fig. 2. Neurobehavioral assessment. The results indicated that immobilization time of the rats, which received nanoparticle increased, while sucrose consumption decreased significantly. Plot proved neurobehavioral abnormalities were dose dependent. Each value indicated the mean \pm S.E.M. Asterisk symbols showed significant changes by $\mathbf{p}<\mathbf{0 . 0 5}$. 


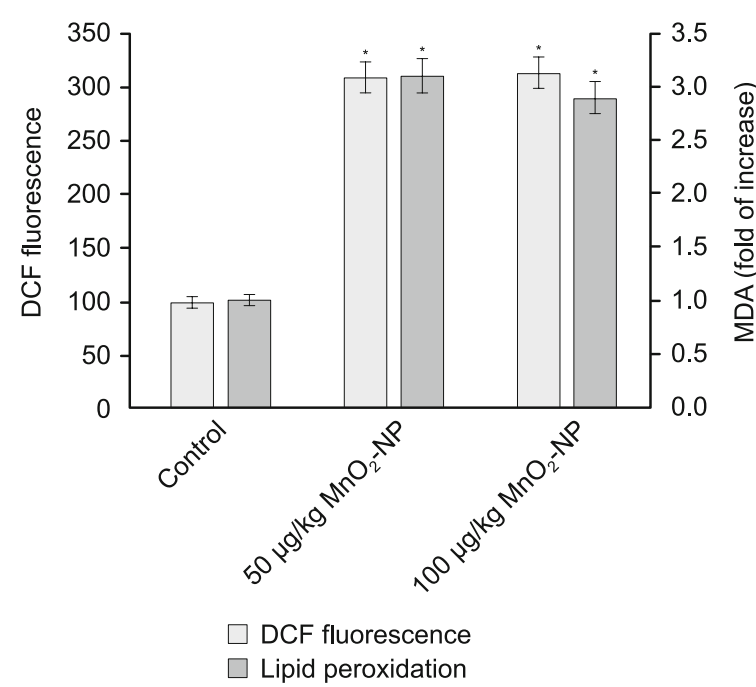

Fig. 3. Oxidative stress evaluation in hippocampus tissue. Increasing of the DCF fluorescence in nanoparticle received rats refers to ROS overproduction in the presence of $\mathrm{MnO}_{2}$-NP. Malondialdehyde were measured as the final production of lipid peroxidation in nanoparticle treated rats and the control. Results showed $\mathrm{MnO}_{2}-\mathrm{NP}$ dose had an important effect on ROS overproduction and Malondialdehyde concentration. Each data indicated the mean \pm S.E.D Asterisk symbols showed significant changes by $\mathrm{p}<0.05$.

\section{$\mathrm{MnO}_{2}-\mathrm{NP}$ induced oxidative stress in hippocampus tissue}

One of important damaging effects of nanoparticles with a high reactive surface area is oxidative stress $(5,7)$. CNS is very susceptible tissue to oxidative stress therefore we investigated whether the intraperitoneally injection of $\mathrm{MnO}_{2}-\mathrm{NP}$ created oxidative stress in hippocampus tissue; so ROS content and MDA level were compared in the three experimental groups.

\section{ROS measurement}

Reactive oxygen species (ROS) are chemically reactive molecules commonly produced by mitochondria during normal metabolism in low concentration, however increased in mitochondrial dysfunction and if the cell is damaged (21). Therefore, a direct ROS measurement will provide a useful report of the oxidative state of the hippocampus tissue related to the experimental groups. Figure 3 revealed that $\mathrm{MnO}_{2}-\mathrm{NP}$ induced ROS overproduction resulted from a high DCF fluorescence intensity in hippocampus tissue. 50 $\mu \mathrm{g} / \mathrm{kg} \mathrm{MnO}_{2}$-NP administration increased DCF fluorescence intensity up to $308.43 \pm 14.22$, while this parameter for the control of the hippocampus was estimated to $98.34 \pm 10.21$. As shown in Figure 3, an increase of the ROS content was nanoparticle dose dependent and reached $312.86 \pm 21.62$ by $100 \mu \mathrm{g} / \mathrm{kg} \mathrm{MnO}_{2}-\mathrm{NP}$ treatment. Both doses of nanoparticle induced more than 3 folds enhanced ROS production in comparison to the control, but ROS overproduction was not affected significantly by nanoparticle doubling (Fig. 3).

\section{Lipid peroxidation}

Lipid peroxidation (LPO) is the most prevalently used indicator for oxidative stress in tissue and can be used as a marker of cell membrane injuries as well $(19,22)$. Malondialdehyde (MDA) is the final product of lipid peroxidation measured by thiobarbituric acid using a standard method (20). Hippocampus tissue of rats, which received both doses of $\mathrm{MnO}_{2}-\mathrm{NP}$, showed increased MDA about 3 fold than the control (Fig. 3). Figure 3 revealed that 3.1 fold increase in lipid peroxidation was caused by daily injection of $50 \mu \mathrm{g} / \mathrm{kg} \mathrm{MnO}_{2}-\mathrm{NP}$, while $100 \mu \mathrm{g} / \mathrm{kg} \mathrm{MnO}_{2}-\mathrm{NP}$ imposed 2.9 fold change in lipid peroxidation that were significant changes in comparison to the control $(\mathrm{p}<0.05)$.

Nanoparticle treatment significantly reduced catecholamine content of hippocampus

Catecholamine consists of the most important neurotransmitters such as dopamine and norepinephrine, which mediated a variety of functions in CNS such as: motor control, memory, emotion, cognition, and endocrine modulation (23). Decreased levels of catecholamine neurotransmitter are accompanied by some neuropsychiatric disorders, especially epilepsy and Parkinson disease (24). This study compared the catecholamine content of hippocampus tissue related to nanoparticle received groups and

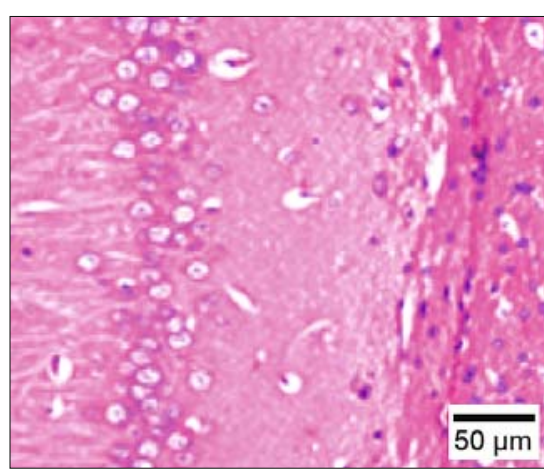

Control

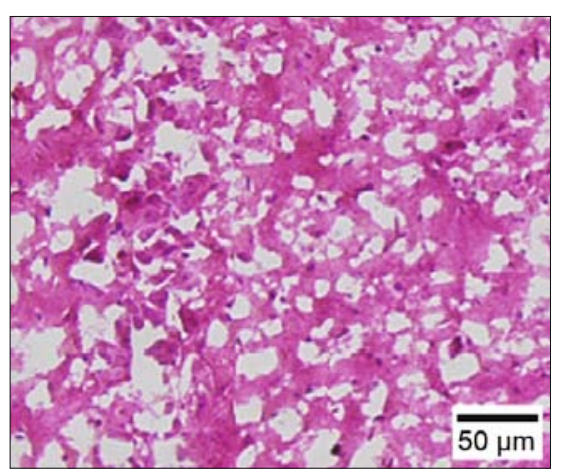

$50 \mu \mathrm{g} / \mathrm{kg} \mathrm{MnO}_{2}-\mathrm{NP}$

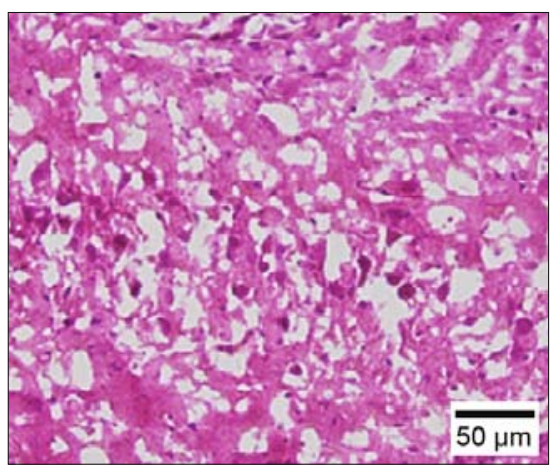

$100 \mu \mathrm{g} / \mathrm{kg} \mathrm{MnO}-\mathrm{NP}$

Fig. 4. Histological studies. Hematoxylin/eosin staining of the hippocampus section was related to nanoparticle treated and the control rats revealed an abnormal tissue appearance than the nanoparticle treated rats. The presence of the apoptotic and necrotic cells in nanoparticle received rat hippocampus refers to harsh damaging effects of $\mathrm{MnO}_{2}-\mathrm{NP}$ in both doses. 
the control. The results showed significant changes in catecholamine concentration imposed by $\mathrm{MnO}_{2}-\mathrm{NP}$ treatment. Catecholamine concentration were measured in the experimental group as follows: $50 \mu \mathrm{g} / \mathrm{kg} \mathrm{MnO}_{2}-\mathrm{NP}, 190.63 \pm 16.54 \mathrm{ng} / \mathrm{mg}$ protein; 100 $\mu \mathrm{g} / \mathrm{kg} \mathrm{MnO}_{2}-\mathrm{NP}, 79.73 \pm 5.89 \mathrm{ng} / \mathrm{mg}$ protein and the control rats, $285.52 \pm 16.54 \mathrm{ng} / \mathrm{mg}$ protein. Our results revealed that manganese oxide nanoparticle caused a significant decrease in catecholamine concentration in a dose dependent manner.

\section{$\mathrm{MnO}_{2}-\mathrm{NP}$ induced harsh changes in tissue appearance}

In order to perform histological studies, rats were anesthetized, and brain tissue was separated from scalp after the end of the experimental duration. Tissue samples were fixed by formalin and stained by hematoxilin-eosin method and then studied under a light microscope (25). By considering biological significance and toxicological importance of the changes, which are found in tissue sections, histological analysis was considered as the biochemical results confirmation. The results showed the presence of necrotic and apoptotic cells in tissue that was administrated 50 and 100 $\mu \mathrm{g} / \mathrm{kg} \mathrm{MnO}_{2}$-NP(Fig. 4). Early apoptotic nuclei had a condensed appearance that was frequently seen in $100 \mu \mathrm{g} / \mathrm{kg} \mathrm{MnO}_{2}-\mathrm{NP}$ received rat hippocampus. As shown in Figure 4, the amounts of apoptotic and necrotic cells seemed to be equal in both doses of nanoparticle received groups.

\section{Discussion}

Nano-sized materials are novel substances usually measured from 1 to $100 \mathrm{~nm}$ size in at least one dimension (1). Nanoparticles have unique features such as: chemical and physical characteristics, shape and high surface area to volume ratio and ability to easily penetrate through membrane and blood brain barrier that facilitate its medical and biological applications (2). $\mathrm{MnO}_{2}-\mathrm{NP}$ is one of the magnetic nanoparticles that is widely used in magnetic data storage, magnetic resonance imaging (MRI), biosensors, radionucleotides absorbance, coatings, plastics, nanowires, nanofibers, and textiles industries (3). By considering a widespread application of $\mathrm{MnO}_{2}$ NP in medicine, biology and industry, exposing of humans and animals to these toxicants is inevitable $(2,3,4)$. Previous studies pproved that nanoparticles had toxic effects in human and animal models in molecular, cellular and physiological levels (26). Approximately all body organs are affected by systemic administration of nanoparticles such as liver, kidney, heart, brain etc. (27). Our previous experiments pproved that daily injection of $15 \mathrm{mg} / \mathrm{kg}$ $\mathrm{Mn}^{2+}$ ion damaged hippocampal neurons and led to Parkinson like syndrome and other molecular damages in hippocampus tissue after 15 days (unpublished data). It is possible that similar neuropsychiatric signs of Parkinson disease and depression like neurobehavior imposed by $\mathrm{MnO}_{2}-\mathrm{NP}$ are caused by similar molecular mechanism (28). Therefore, this study investigated toxic effects of nano- sized $\mathrm{MnO}_{2}$ on hippocampus tissue and cognitive function of the rats. By considering a high surface area to volume ration of nano- sized $\mathrm{MnO}_{2}$ in comparison to chemical $\mathrm{MnCl}_{2}$, we used lower doses of nanoparticle as an effective dose ( 50 and $100 \mu \mathrm{g} / \mathrm{kg}$ ). Two different doses of $\mathrm{MnO}_{2}-\mathrm{NP}$ were used in this study to examine a dose de- pendency. Figure 1 illustrated nanoparticle size from 30 to $60 \mathrm{~nm}$ as well-dispersed solution before injection. We used standard methods to assess depression like behaviors in rats that receive two doses of nanoparticle and the control rats $(12,13)$. Our results showed that intraperitoneal injection of $\mathrm{MnO}_{2}-\mathrm{NP}$ (during 15 days) significantly decreased sucrose consumption and increased immobility time in forced swimming test in the rats that received nanoparticle. Quantitative behavioral assessment in the experimental groups revealed that depression like behavior was manifested nanoparticle dose dependently and was more significant in the rats that received 100 $\mu \mathrm{g} / \mathrm{kg}$ dose. Biochemical analysis showed a decreased acetylcholine content in the hippocampus of the nanoparticle received rats. There is a strong evidence that catecholamine reduction causes cognitive disorders such as: Parkinson, Alzheimer and depression $(7,24)$. Rats that received a high dose of nanoparticle, manifested harsh reduction of catecholamine concentration in the hippocampus accompanied also by depression like behavior signs (Fig. 2).

Comparison of the stained tissue sections in the experimental groups showed a harsh abnormal manifestation in nanoparticle administrated hippocampus in comparison to the control (Fig. 4). The presence of the condensed apoptotic cells and necrotic cells proved that nanoparticle damaging effects on the hippocampus tissue might be due to a harsh oxidative stress that occurred by ROS overproduction (Fig. 2) (29). A small size of $\mathrm{MnO}_{2}-\mathrm{NP}$ causes its easy to penetrate to the hippocampus and its damaging effects (1, 2). As previously proved, nanoparticles have a high surface area and also reactive surface that attacks the cellular components and damages them, what leads cells to the apoptosis and necrosis (1). The nature of nanoparticles that were used in this study $\left(\mathrm{Mn}^{2+}\right)$ causes Parkinson like syndrome as illustrated in our previous studies (unpublished data). This study also showed that the signs of cognitive disorder in rats, which were intoxicated by $\mathrm{MnO}_{2}-$ NP, might be due to damage resulted from the size and/or nature of the toxicant. While literature showed that nanomaterials with different nature create oxidative damage and neurodegeneration in CNS based on their size $(3,27)$, oxidative stress resulting from $\mathrm{MnO}_{2}-\mathrm{NPwas}$ accompanied by hippocampal cell death. Previously proved cell death in the presence of $\mathrm{Mn}^{2+}$ mainly occurred in catecholamine producing cells resulted in reduced catecholamine levels (30). It is possible that massive degeneration in hippocampus tissue, that have an important role in learning and thinking, led to depression like behavior and anhedonia as observed in the nanoparticle treated rats (31). The results proved that nanoparticle doubling creates an extensive molecular damage, which led to severe neurobehavioral abnormalities.

Our study investigated one of the most prevalently used nanoparticles $\left(\mathrm{MnO}_{2}-\mathrm{NP}\right)$ toxic effects on the hippocampus tissue. Previously approved $\mathrm{Mn}^{2+}$ ion exposing caused cognitive disorder and depression like behavior in humans and rats, therefore we assessed the behavioral and biochemical alterations in rats that were treated by different doses of manganese dioxide nanoparticle. The results confirmed that an increased ROS production in hippocampus was related to nanoparticle treated rats accompanied by an increased lipid peroxidation as well. Manganese nanoparticle administration reduced the catecholamine content of hippocam- 
pus dose dependently. The mentioned molecular and biochemical alterations created an abnormal tissue appearance in hippocampal tissue in $\mathrm{MnO}_{2}-\mathrm{NP}$ treated rats by the presence of apoptotic and necrotic cells. $\mathrm{MnO}_{2}-\mathrm{NP}$ intoxication led to depression like behavior in a dose dependent manner. As the results showed, cognitive dysfunction and molecular alterations in a high dose of nanoparticle is more significant, therefore manganese nanoparticle that is used in medicine and industry should be limited by considering a toxic dose. While deposited nanoparticles should be diluted and neutralized before release as a sewage.

\section{References}

1. Jani P, Halberd GW, Langridge J, Florence AT. Nanoparticle uptake by the gastrointestinal mucosa: quantitation and particle dependency. $\mathrm{J}$ Pharm Pharmacol 1990; 42: 821-826.

2. Indira TK, Lakshmi PK. Magnetic Nanoparticles - Review. Int J Pharm 2010; 3: 1035-1042.

3. Buzea C, Pacheco II, Robbie K. Nanomaterials and nanoparticles: sources and toxicity. Biointerphases 2007; 2 (4): 17-71.

4. Long Z, Jiang Y, Li X, Fadel W, Xu J, Yeh C, Long L, Luo H, Harezlak J, Murdoch JB. Vulnerability of welders to manganese exposure-A neuroimaging study. Neurotoxicol 2014; 45: 285-292.

5. Peres TV, Schettinger MR, Chen P, Carvalho F, Avila DS, Bowman AB, Aschner M. Manganese-induced neurotoxicity: a review of its behavioral consequences and neuroprotective strategies. BMC Pharmacol Toxicol 2016; 17: 57.

6. Takeda A. Manganese action in brain function. Brain Res Rev 2003; 41: 79-87.

7. Yousefi Babadi V, Sadeghi L, Amraie E, Rezaei M, Malekirad AA, Abarghouei Nejad M. Manganese toxicity in the central nervous system: Decreeing of catecholamine in rat's brains. Health 2013; 5: 2146-2149.

8. Sarnyai Z, Sibille EL, Pavlides C, Fenster RJ, McEwen BS, Toth M. Impaired hippocampal-dependent learning and functional abnormalities in the hippocampus in mice lacking serotonin1A receptors. Proc Natl Acad Sci USA 2000; 97: 14731-14736.

9. Robison G, Zakharova T, Fu S, Jiang W, Fulper R, Barrea R, Zheng W, Pushkar Y. X-ray Fluorescence Imaging of the Hippocampal Formation After Manganese Exposure. Metallomics 2013; 5: 1554-1565.

10. Zhang Y, Yang Y, Zhang Y, Zhang T, Ye M. Heterogeneous oxidation of naproxen in the presence of $\alpha-\mathrm{MnO} 2$ nanostructures with different morphologies. Appl Catal B. 2012; 127: 182-189.

11. Mousavi Z, Hassanpourezatti M, Najafizadeh P, Rezagholian S, Rhamanifar MS, Nosrati N. Effects of Subcutaneous Injection MnO2 Micro- and Nanoparticles on Blood Glucose Level and Lipid Profile in Rat. Iran J Med Sci 2016; 41 (6): 518-524.

12. Yankelevitch-Yahav R, Franko M, Huly A, Doron R. The Forced Swim Test as a Model of Depressive-like Behavior. J Vis Exp 2015; 2015 : 52587.

13. Overstreet DH. Modeling depression in animal models. Methods Mol Biol 2012; 829: 125-144.

14. Latchoumycandane C, Anantharam V, Kitazawa M, Yang Y, Kanthasamy A, Kanthasamy AG. Protein kinase C $\delta$ is a key downstream mediator of manganese-induced apop- tosis in dopaminergic neuronal cells. J Pharmacol Exp Ther 2005; 313 (1): 46-55.
15. Felice LJ, Felice JD, Kissinger PT. Determination of catecholamines in rat brain parts by reverse-phase ion-pair liquid chromatography. J Neurochem 1978; 31: 1461-1465.

16. Feller DJ, O’Dell BL. Dopamine and nore- pinephrine in discrete areas of the copper-deficient rat brain. J Neurochem 1980; 34: 1259-1263.

17. Lebel CP, Ischiropoulos H, Bondy SC. Evaluation of the probe $2^{\prime}, 7^{\prime}$-dichlorofluorescin as an indicator of reactive oxygen species formation and oxidative stress. Chem Res Toxicol 1992; 5: 227-231.

18. Bradford MM. Rapid and sensitive method for the quantitation of microgram quantities of protein utilizing the principle of protein-dye binding. Anal Biochem 1976; 72: 248-254.

19. Niki E. Lipid peroxidation products as oxidative stress biomarkers. Biofactors 2008; 34: 171-180.

20. Buege JA, Aust SD. Microsomal lipid, Peroxidation. In: Flesicher S, Packer L (Eds.). Methods in Enzymology. New York: Academic Press, 1978.

21. Gao L, Laude K, Cai H. Mitochondrial Pathophysiology, Reactive Oxygen Species, and Cardiovascular Diseases. Vet Clin North Am Small Anim Pract 2008; 38: 137.

22. Barrera G. Oxidative Stress and Lipid Peroxidation Products in Cancer Progression and Therapy. ISRN Oncol 2012; 2012: 137289.

23. Kobayashi K. Role of Catecholamine Signaling in Brain and Nervous System Functions: New Insights from Mouse Molecular Genetic Study. J Investig Dermatol Symp Proc 2001; 6: 115-121.

24. Sadeghi L, Rizvanov AA, Salafutdinov II, Dabirmanesh B, Sayyah M, Fathollahi Y, Khajeh K. Hippocampal asymmetry: differences in the left and right hippocampus proteome in the rat model of temporal lobe epilepsy. J Proteomics 2017; 154: 22-29.

25. Dhandapani S, Subramanian VR, Rajagopal S, Namasivayam N. Hypolipidemic effects of Cuminum cyminum L. on alloxan-induced diabetic rats. Pharmacol Res 2002; 46: 251-255.

26. Sadeghi L, Tanwir F, Yousefi Babadi V. In vitro toxicity of iron oxide nanoparticle: oxidative damages on Hep G2 cells. Exp Toxicol Pathol 2015; 67 (2): 197-203.

27. Yang L, Kuang H, Zhang W, Aguilar ZP, Wei H, Xu H. Comparisons of the biodistribution and toxicological examinations after repeated intravenousadministration of silver and gold nanoparticles in mice. Sci Rep 2017; 12; 7 (1): 3303.

28. Kwakye GF, Paoliello MM, Mukhopadhyay S, Bowman AB, Aschner M. Manganese-Induced Parkinsonism and Parkinson's Disease: Shared and Distinguishable Features. Int J Environ Res Public Health 2015; 12: 7519-7540.

29. Yousefi Babadi V, Najafi L, Najafi A, Gholami H, Beigi Zarji ME, Golzadeh J, Amraie E, Shirband A. Evaluation of iron oxide nanoparticles effects on tissue and enzymes of liver in rats. J Pharma Biomed Sci 2012; 23: 1-5.

30. Anton AH, Sayre DF. The distribution of dopamine and dopa in various animals and a method for their determination in diverse biological material. J Pharmacol Exp Ther 1964; 145: 326-336.

31. Finke C, Prüss H, Heine J, Reuter S, Kopp UA, Wegner F, Then Bergh F, Koch S, Jansen O, Münte T, Deuschl G, Ruprecht K, Stöcker W, Wandinger KP, Paul F, Bartsch T. Evaluation of Cognitive Deficits and Structural Hippocampal Damage in Encephalitis With Leucine-Rich, Glioma-Inactivated 1 Antibodies. JAMA Neurol 2017; 74 (1): 50-59.

Received February 19, 2018. Accepted March 12, 2018. 